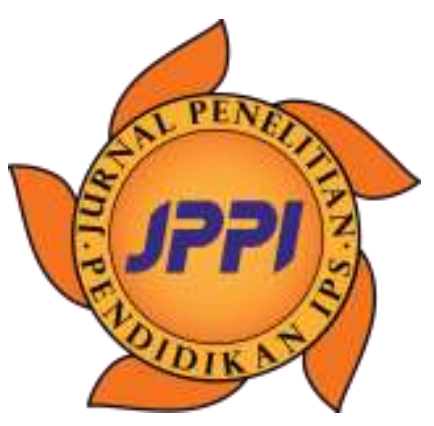

Info Artikel

Keyword:

Outdoor Based Character Citizen Learning Models, Students Interest, Critical Thinking, Students

Achievement.

Korespondensi Penulis:

Linda Kristinawati:

E-mail:

lKristinawatilinda83@gmail.

ISSN (print): 1858-4985

ISSN (on-line): 2721-8821

\section{Pengaruh Model Pembelajaran Charakter Project Citizen Berbasis Outdoor, Minat Belajar dan Ber- fikir Kritis Terhadap Prestasi Siswa}

\author{
Linda Kristinawati ${ }^{1}$ \\ Pascasarjana Universitas Kanjuruhan Malang \\ Kristinawatilinda83@gmail.com \\ ${ }^{1}$ Program Pascasarjana Universitas Kanjuruhan Malang \\ Jl. S. Supriyadi No. 48 Malang, 65148, Indonesia
}

\section{Abstract}

The purpose of this research 1) To know the influence of the outdoor based character project citizen learning model toward the students achievement of partially fifth grade students at Mutiara Harapan Elementary School Lawang; 2) To know the influence of learning interest toward students learning achievement of partially fifth grade students at Mutiara Harapan Elementary School Lawang; 3) To know the influence of critical thinking toward students learning achievement of partially fifth grade students at Mutiara Harapan Elementary School Lawang 4) To know the influence of outdoor based character project citizen learning model, students interest, and critical thinking toward students learning achievement of simultaneously fifth grade students at Mutiara Harapan Elementary School Lawang.Based on research objectives which basically research that is used including applied research. Applied research is aimed at solving practical life problems. As the techniques used in collecting data in this research are documentation and questionnaires. The analysis on this research using multiple regression analysis with the SPSS program for Windows.The result of this research showed that 1) The first hypothtesis test results obtained no significant influence from outdoor based character project citizen models toward students learning achievement of partially fifth grade students at Mutiara Harapan Elementary School Lawang. Data analysis result with pearson test obtained the coefficient correlation of 0,121 with significancy of 0,343. Therefore it can be said that the effect of X1 on $Y$ is not significant. Ho accepted and Hi rejected. 2) The second hypothesis test obtained any significant influence from outdoor based character project citizen models toward students learning achievement of partially fifth grade students at Mutiara Harapan Elementary School Lawang. Data analysis result with pearson test obtained the coefficient correlation of 0,411 with significancy of 0,001. Therefore it can be said that the influence of X2 on $Y$ is significant. Ho rejected and Hi accepted. 3) The third hypothesis test results obtained any significant influence of critical thinking toward students learning achievement of partially fifth grade students at Mutiara Harapan Elementary School Lawang. Data analysis result with pearson test obtained the coefficient correlation of 0,472 with significancy of 0,000. Therefore it can be said that the influence of $X 3$ on $Y$ is significant. Ho rejected and $\mathrm{Hi}$ accepted. 4) The fourth hypothesis test result say there is influence of outdoor study based character project citizen models, learning interest and critical thinking toward students achievement of simultaneously fifth grade students at Mutiara Harapan Elementary School Lawang. The value of the determinant coefficient $(R)$ of 0,652 which means that the independent variable is outdoor based character project citizen models (X1), learning interest (X2), and critical thinking (X3) able to explain the dependent variable students achievement $(Y)$ of 65,2\% while the rest is 34,8\% explained by another variable outside the model. It shows that the dependent variable has a significance influence.

\section{PENDAHULUAN}


Pendidikan merupakan bidang yang harus diutamakan karena para siswa mempunyai berbagai potensi dalam dirinya. Belajar akan lebih bermakna jika siswa mengalami apa yang dipelajarinya, bukan mengetahuinya. Pembelajaran yang berorientasi pada penguasaan materi terbukti berhasil dalam kompetisi mengingat jangka pendek, tetapi gagal dalam membekali anak memecahkan persoalan dalam kehidupan jangka panjang dan kita harus bisa melakukan berbagai pendekatan dalam segala hal (Amri dan Ahmadi, 2010). Secara khusus Syaiful Bahri Djamarah (2008:177) mengemukakan bahwa interaksi dari lingkungan alami dan lingkungan sosial budaya selalu terjadi dalam mengisi kehidupan anak didik serta mempunyai pengaruh yang signifikan terhadap belajar anak di sekolah.

Model pembelajaran mengacu pada pendekatan pembelajaran yang akan digunakan, termasuk di dalamnya tujuan pengajaran, tahap-tahap dalam kegiatan pembelajaran, lingkungan pembelajaran dan pengelolaan kelas (Trianto, 2014:51).

Masalah yang timbul dari faktor guru yaitu guru SD Mutiara Harapan Kecamatan Lawang Kabupaten Malang kurang mampu mengembangkan metode pembelajaran yang inovatif dan masih menerapkan pembelajaran yang konvensional dalam hal ini metode yang sering digunakan oleh guru adalah metode ceramah. Charakter project citizen berbasis outdoor adalah model dimana guru mengajak siswa belajar di luar ruangan dengan memanfaatkan lingkungan sekitar sebagai sumber belajar, untuk melihat peristiwa langsung di lapangan dengan tujuan untuk mengenalkan peserta didik dengan lingkungannya.

\section{METODE}

Jenis Penelitian: Penelitian yang digunakan termasuk dalam penelitian kuantitatif dengan menggunakan penelitian terapan dan bertujuan penjelasan (explanation).

Waktu Penelitian dan Tempat Penelitian : Tahun ajaran 2018-2019 semester 1 dan bertempat di SD Mutiara Harapan Lawang

Target/Subyek Penelitian: Responden adalah siswa kelas V SD Mutiara Harapan Lawang Kecamatan Lawang Kabupaten Malang Tahun Ajaran 2018/2019

Prosedur: Penelitian ini juga bertujuan memberikan penjelasan hal-hal yang berkaitan dengan variabel bebas dan tergantung serta menemukan dan melaporkan antara aspek-aspek dari fenomena yang ditelaah. Penelitian ini termasuk penelitian terapan, metode deskriptif, tingkat riset korelasi dengan jenis data kuantitatif.

Teknik Analisis Data: Penelitian ini menggunakan beberapa teknik pengumpulan antara lain dengan menggunakan skala likert, kuesioner/angket dan observasi.Data hasil kuesioner berupa jawaban responden dari variabel.

\section{HASIL DAN PEMBAHASAN \\ Hasil Penelitian \\ Model CPC Outdoor Study (X1)}

Tabel 1. Distribusi Frekwensi Skor Hasil Sebaran Angket Variabel X1 Cpc outdoor study

\begin{tabular}{|c|c|c|c|c|c|c|}
\hline & & & Frequency & Percent & Valid Percent & Cumulative Percent \\
\hline \multirow[t]{10}{*}{ Valid } & & 1 & 16 & 44,4 & 44,4 & 44,4 \\
\hline & & 1 & 1 & 2,8 & 2,8 & 47,2 \\
\hline & 6 & & & & & \\
\hline & & 2 & 1 & 2,8 & 2,8 & 50,0 \\
\hline & 4 & $?$ & $?$ & & & 556 \\
\hline & 5 & 2 & 2 & 5,6 & 5,6 & 55,6 \\
\hline & 4 & 3 & 5 & 13,9 & 13,9 & 69,4 \\
\hline & & 3 & 2 & 5.6 & 56 & 750 \\
\hline & 5 & & & & & \\
\hline & & 3 & 2 & 5,6 & 5,6 & 80,6 \\
\hline
\end{tabular}




\begin{tabular}{|c|c|c|c|c|}
\hline 7 & 2 & 5,6 & 5,6 & 86,1 \\
\hline 0 & 1 & 2,8 & 2,8 & 88,9 \\
\hline 2 & 1 & 2,8 & 2,8 & 91,7 \\
\hline 4 & 2 & 5,6 & 5,6 & 97,2 \\
\hline 8 & 1 & 2,8 & 2,8 & 100,0 \\
\hline otal & 36 & 100,0 & 100,0 & \\
\hline
\end{tabular}

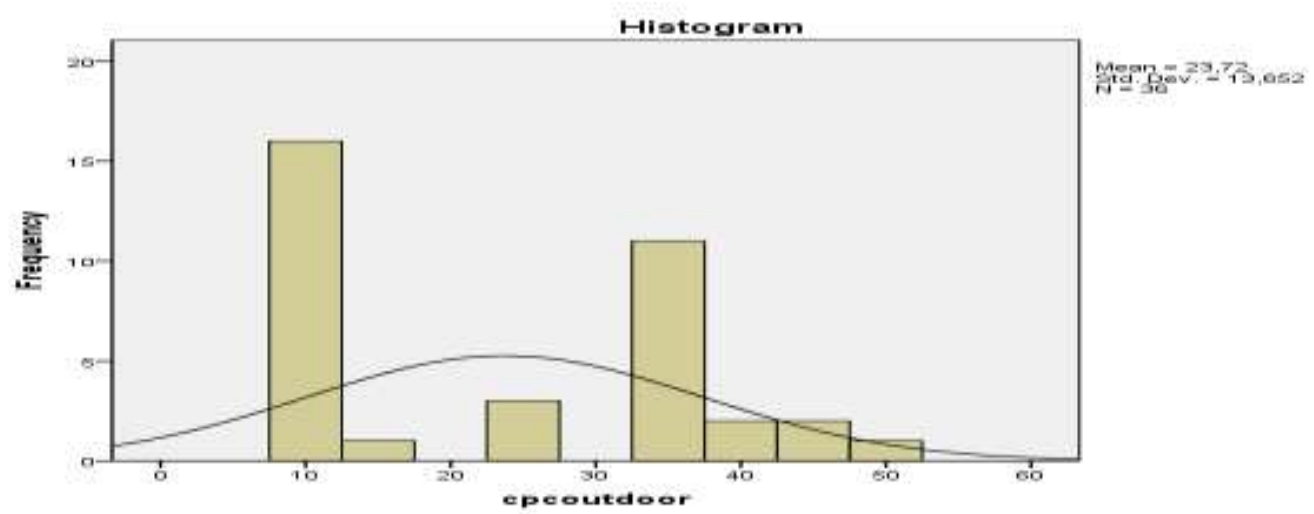

Gambar 1. Histogram Variabel Model CPC Berbasis Outdoor (X1)

Keadaan variabel X1 setelah diadakan penyebaran angket dan peskoran berdasarkan skala likert menunjukkan bahwa total skor terendah variabel X1 adalah 10, sedangkan skor tertinggi adalah 48. Dan jika dibandingkan dengan skor keseluruhan yakni 50, maka skor untuk variabel X1 rata-rata 23,72 .

Variabel Minat Belajar (X2)

Tabel 2. Distribusi Frekwensi Skor Hasil Sebaran Angket Variabel X2

\begin{tabular}{|c|c|c|c|c|c|c|}
\hline Valid & & Frequency & Percent & & Valid Percent & Cumulative Percent \\
\hline & & 2 & 1 & 2,8 & 2,8 & 2,8 \\
\hline & 2 & & & & & \\
\hline & & 2 & 1 & 2,8 & 2,8 & 5,6 \\
\hline & 3 & 2 & 1 & 28 & 28 & 83 \\
\hline & 5 & & & 2,0 & 2,0 & \\
\hline & & 2 & 1 & 2,8 & 2,8 & 11,1 \\
\hline & 6 & & & & & \\
\hline & & 2 & 1 & 2,8 & 2,8 & 13,9 \\
\hline & 7 & 2 & 2 & 56 & 56 & 194 \\
\hline & 9 & 2 & 2 & J,0 & J,0 & 19,4 \\
\hline & & 3 & 1 & 2,8 & 2,8 & 22,2 \\
\hline & 0 & & & & & \\
\hline & & 3 & 3 & 8,3 & 8,3 & 30,6 \\
\hline & 1 & & & & & \\
\hline & 3 & 3 & 3 & 8,3 & 8,3 & 38,9 \\
\hline & 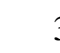 & 3 & 4 & 11,1 & 11,1 & 50,0 \\
\hline & 3 & & & & & \\
\hline & 5 & 3 & 3 & 8,3 & 8,3 & 58,3 \\
\hline & 6 & 3 & 1 & 2,8 & 2,8 & 61,1 \\
\hline
\end{tabular}




\begin{tabular}{|c|c|c|c|c|}
\hline 3 & 4 & 11,1 & 11,1 & 72,2 \\
\hline 8 & 2 & 5,6 & 5,6 & 77,8 \\
\hline 9 & 3 & 8,3 & 8,3 & 86,1 \\
\hline 0 & 2 & 5,6 & 5,6 & 91,7 \\
\hline 1 & 1 & 2,8 & 2,8 & 94,4 \\
\hline 3 & 1 & 2,8 & 2,8 & 97,2 \\
\hline $5^{4}$ & 1 & 2,8 & 2,8 & 100,0 \\
\hline otal & 36 & 100,0 & 100,0 & \\
\hline
\end{tabular}

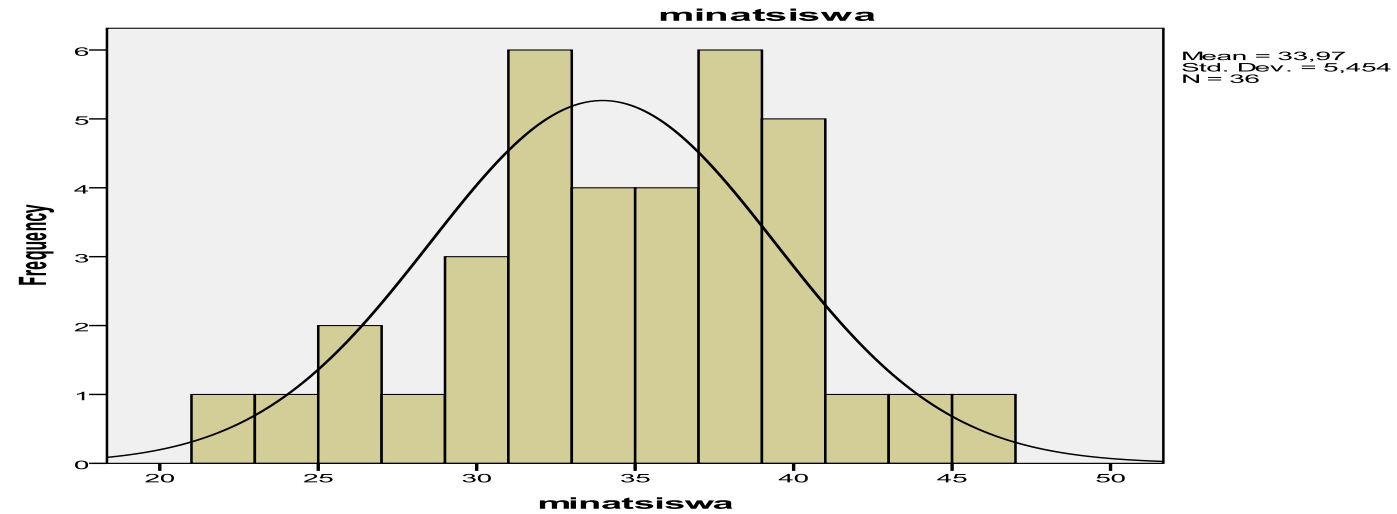

Gambar 2. Histogram Variabel Minat Belajar (X2)

Keadaan Variabel X2 setelah diadakan penyebaran angket dan penskoran berdasarkan skala likert menunjukkan bahwa total skor terendah variabel X2 adalah 22, sedangkan skor tertinggi adalah 45 . Dan jika dibandingkan dengan skor keseluruhan yakni 50, maka rata-rata skor untuk variabel X2 adalah 33,97 .

\section{Variabel Berfikir Kritis (X3)}

Tabel 3. Distribusi Frekwensi Skor Hasil Sebaran Angket Variabel X3

\begin{tabular}{ccccccc} 
& \multicolumn{2}{c}{ Frequency } & Percent & \multicolumn{2}{c}{ Valid Percent } & Cumulative Percent \\
\hline Valid & 1 & 1 & 2,8 & 2,8 & 8,8 \\
& 7 & 2 & 2 & 5,6 & 5,6 & 11,1 \\
3 & 2 & 1 & 2,8 & 2,8 & 13,9 \\
5 & 3 & 1 & 2,8 & 2,8 & 22,2 \\
1 & 3 & 3 & 8,3 & 8,3 & 25,0 \\
2 & 3 & 1 & 2,8 & 2,8 & 27,8
\end{tabular}




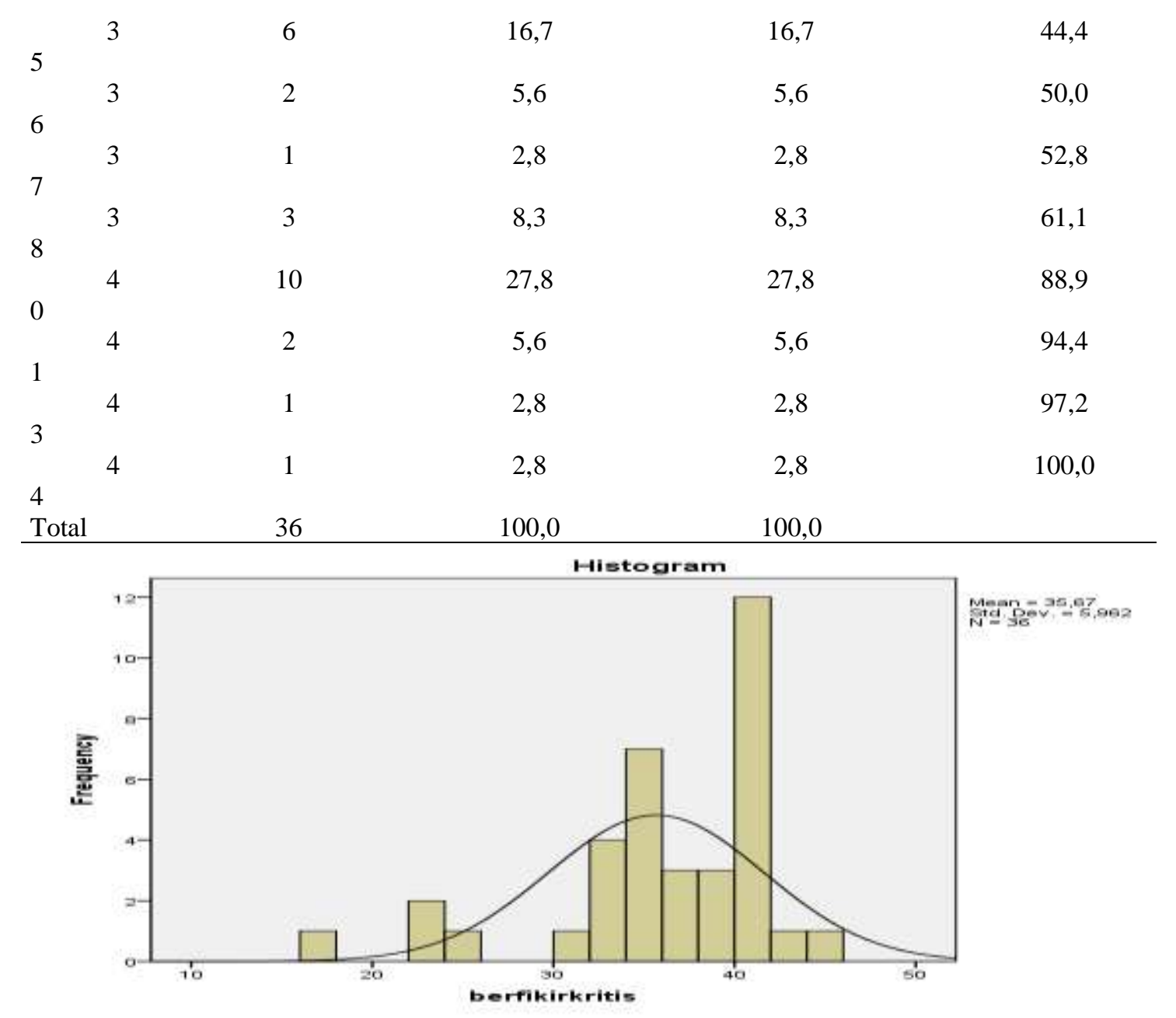

Gambar 3. Histogram Variabel Minat Belajar (X3)

Keadaan Variabel X3 setelah diadakan penyebaran angket dan penskoran berdasarkan skala likert menunjukkan bahwa total skor terendah variabel X3 adalah 17, sedangkan skor tertinggi adalah 44. Dan jika dibandingkan dengan skor keseluruhan yakni 50, maka skor untuk variabel X3 dengan rata-rata 36,67 .

\section{Variabel Prestasi Belajar (Y)}

Tabel 4. Distribusi Frekwensi Skor Hasil Sebaran Angket Variabel Y

\begin{tabular}{ccccccc}
\hline & \multicolumn{2}{c}{ Frequency } & Percent & \multicolumn{2}{c}{ Valid Percent } & Cumulative Percent \\
\hline Valid & 7 & 2 & 5,6 & 5,6 & 5,6 \\
& 7 & 2 & 5,6 & 5,6 & 11,1 \\
8 & 7 & 3 & 8,3 & 8,3 & 22,2 \\
9 & 8 & 1 & 2,8 & 2,8 & 27,8 \\
0 & 8 & 2 & 5,6 & 5,6 & 33,3 \\
1 & 8 & 2 & 5,6 & 5,6 & 44,4 \\
2 & 8 & 4 & 11,1 & 11,1 &
\end{tabular}




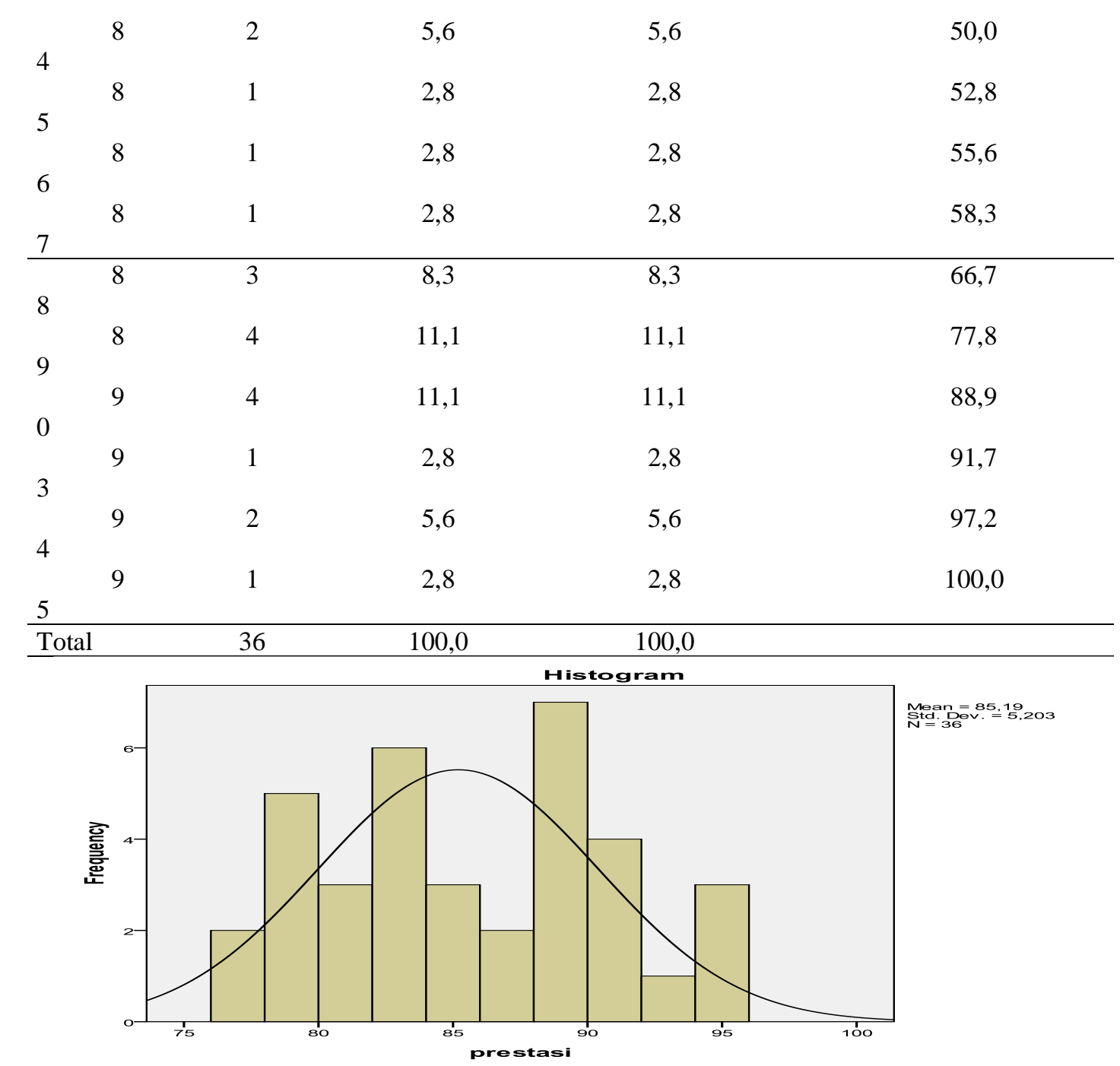

Gambar 4. Diagaram Variabel Prestasi Siswa (Y)

Keadaan Variabel Y setelah diadakan penyebaran angket dan penskoran berdasarkan skala likert menunjukkan bahwa total skor terendah variabel Y adalah 77, sedangkan skor tertinggi adalah 95. Dan jika dibandingkan dengan skor keseluruhan yakni 100, maka skor untuk variabel Y termasuk dalam kategori baik dengan rerata 85,19.Nilai koefisien determinan (R) sebesar 0,652 yang berati bahwa variabel bebas yaitu model character project citizen berbasis outdoor (X1), minat belajar (X2), dan berfikir kritis (X3) mampu menjelaskan variabel terikat prestasi siswa (Y) sebesar 65,2\% sedangkan sisanya sebesar $34,8 \%$ dijelaskan oleh variabel lain di luar model.

\section{Pembahasan}

1. Tidak Ada Pengaruh Model Character Project Citizen Berbasis Outdoor Terhadap Prestasi Siswa Kelas V SD Mutiara Harapan Lawang Secara Parsial.

Hasil analisis data dengan uji pearson diperoleh koefesien korelasi sebesar 0,121 dengan signifikansi 0,343. Dengan demikian dapat dikatakan tidak ada pengaruh X1 terhadap Y secara signifikan. Hal ini tidak berarti model character project citizen berbasis oudoor kurang penting terhadap tercapainya prestasi belajar, tetapi dalam kenyataannya tercapainya pembelajaran yang optimal memerlukan suatu model pembelajaran yang bervariasi.

2.Terdapat Pengaruh Minat Belajar Terhadap Prestasi Siswa Kelas V SD Mutiara Harapan Lawang Secara Parsial.

Hasil analisis data dengan uji pearson diperoleh koefesien korelasi sebesar 0,411 dengan signifikansi 0,001 Artinya X2 ada pengaruh terhadap Y secara signifikan. 
3.Terdapat Pengaruh Berfikir Kritis Terhadap Prestasi Siswa Kelas V SD Mutiara Harapan Lawang Secara Parsial.

Hasil analisis data dengan uji pearson diperoleh koefesien korelasi sebesar 0,472 dengan signifikansi 0,000. Artinya X3 memiliki pengaruh terhadap Y secara signifikan .

4. Terdapat Pengaruh Model Character Project Citizen Berbasis Outdoor Study, Minat Belajar, Berfikir Kritis Terhadap Prestasi Siswa Kelas V SD Mutiara Harapan Lawang Secara Simultan.

Ini dibuktikan dengan nilai koefisien determinan $(\mathrm{R})$ sebesar 0,652 yang berati bahwa variabel bebas yaitu model character project citizen berbasis outdoor (X1), minat belajar (X2), dan berfikir kritis (X3) mampu menjelaskan variabel terikat prestasi siswa (Y) sebesar 65,2 \% sedangkan sisanya sebesar $34,8 \%$ dijelaskan oleh variabel lain di luar model.

\section{SIMPULAN DAN SARAN \\ Kesimpulan}

Berdasarkan uraian hasil penelitian pada bab sebelumnya, maka hasil penelitian ini dapat disimpulkan sebagai berikut.

1. Hasil uji hipotesis pertama diperoleh tidak ada pengaruh yang signifikan model $c p c$ berbasis outdoor study terhadap prestasi belajar siswa kelas V SD Mutiara Harapan Lawang secara parsial.

2. Hasil uji hipotesis kedua diperoleh ada pengaruh yang signifikan minat belajar terhadap prestasi belajar siswa kelas V SD Mutiara Harapan Lawang secara parsial.

3. Hasil uji hipotesis ketiga diperoleh ada pengaruh yang signifikan berfikir kritis terhadap prestasi belajar siswa kelas V SD Mutiara Harapan Lawang secara parsial.

4. Hasil uji hipotesis keempat diperoleh ada pengaruh yang signifikan model charakter project citizen berbasis outdoor, minat belajar, berfikir kritis, terhadap prestasi belajar siswa kelas V SD Mutiara harapan Lawang secara simultan.

\section{Saran}

1. Faktor cpc(character project citizen) outdoor study, minat belajar, berfikir kritis berpengaruh terhadap prestasi siswa hendaknya mendapat perhatian dalam pengembangan lembaga pendidikan di masa depan agar dapat menciptakan output dan outcome yang bermutu dalam mendukung capaian tujuan pendidikan yang diharapkan sesuai dengan visi misi yang ada, khususnya SD Mutiara Harapan Lawang Kabupaten Malang.

2.Hasil-hasil yang sudah dicapai lembaga selama ini merupakan sumbangan nyata para siswa, guru dalam pengabdiannya, namun belum merupakan hasil yang optimal di SD Mutiara Harapan Lawang Kabupaten Malang. Karena itu siswa, guru dan karyawan lainnya perlu di dorong dari berbagai aspek seperti pemberian tugas, mengikuti pendidikan dan latihan serta pemberian penghargaan yang sesuai, sehingga dapat merangsang kreativitasnya karena ada harapan yang mungkin dicapai.

\section{DAFTAR RUJUKAN}

Amri dan Ahmadi,2010.Proses Pembelajaran Inovatif dan Kreatif, Dalam Kelas. Jakarta:PT Prestasi Pustakarya.

Coleman dan Hammen (Megalia 2010 : 12). Pembelajaran Matematika dengan Menggunakan Model Assurance, Relevance, Interest, Assesment, Statisfication (ARIAS) dalam Upaya Meningkatkan Kemampuan berfikir Kreatif Siswa. Skripsi FPMIPA UPI.Bandung :Tidak diterbitkan.

Al Tin Sumartini,2012 Pengaruh Pembelajaran Berbasis Project Citize Terhadap Pengembangan Kompetensi Warganegra Di Era Globalisasi. Uiversitas Pendidikan Indonesia : Repository.Upi.Edu)

Ali Mahmudi. Mengukur Kemampuan Berpikir Kreatif. (Yogyakarta: UNY Yogyakarta. 2010).

Ali Mahmudi. Pemecahan masalah dan Berpikir Kreatif. (Palembang: Universitas Sriwijaya Palembang, 2008)

Aziz Saefudin, Abdul. Pengembangan Kemampuan Berpikir Kreatif Siswa Dalam Pembelajaran Matematika Dengan Pendekatan Pendidikan Matematika Realistik.( Yogyakarta: Universitas PGRI Yogyakarta. 2012)

Baharudin (2009:162).Pendidikan dan Psikologi Perkembangan. Yogyakarta:Ar-Ruuzz Media Bonoe, Pono. (2003). Kamus Musik.

Budimansyah (2009:1). Paradigma Pembangunan Pendidikan.Jakarta 
Dalyono, Psikologi Pendidikan, Jakarta: Rineka Cipta, 2001.

Depdikbud, Kamus Besar Bahasa Indinesia, Jakarta: Balai Pustaka, 2002.

Ika Susilawati. Perbandingan Peningkatan Kemampuan Berpikir Kritis Didasarkan pada Model STAD dan PBL pada Mata Pelajaran IPS-Ekonomi Siswa Kelas VIII SMP Raden Fatah Batu.

Koes, 2003. Strategi Pembelajaran.Jurusan Fisika FP MIPA UM. Malang : Alumni.

Luqman,2017.Penerapan Model Pembelajaran Project Citizen.Mataram : Erlangga.

Martini,1992. Metode Penelitian Bidang Sosial.Yogyakarta:Gadjah Mada Universitas Press.

Muanisah. Profil Kemampuan Berpikir Kreatif Siswa dalam Menyelesaikan Masalah Terbuka (Open Ended) di Kelas VII. SMP Sunan Ampel Menganti Gresik-tidak dipublikasikan (IAIN Sunan Ampel Surabaya. 2010) tidak dipublikasikan)

Muhammad Angry Fajar Purba, Gender dalam Psikologi,.blogspot.com/2013/06/ 3835.html, diakses tanggal 1 januari 2013 